\title{
10
}

\section{RELIABILITY OF ANCHORED MONOLITH STRUCTURES UNDER CORROSION EFFECTS}

\author{
Dan M. Frangopol ${ }^{a}$, Milan Chakravorty ${ }^{a}$, Reed L. Mosher ${ }^{b}$ and Jan E. Pytte ${ }^{a}$ \\ ${ }^{a}$ Department of Civil, Environmental, and Architectural Engineering, University of Col- \\ orado, Boulder, Colorado 80309-0428, USA \\ ${ }^{b}$ USAE Waterways Experiment Station, 3909 Halls Ferry Road, Vicksburg, MS 39180- \\ 6199, USA
}

A research program at the University of Colorado at Boulder investigated time-variant reliability assessment of concrete gravity structures founded on rock for different loading conditions. In the course of this investigation, a methodology was developed for reliability analysis of anchored monolith structures under corrosion effects. This paper presents a brief overview of the methodology for time-variant reliability assessment of existing concrete gravity structures under corrosion effects.

\section{INTRODUCTION}

As stated recently in a U.S. Army Corps of Engineers technical letter [1] "Inland navigation structures are a vital link in the national infrastructure. Over $40 \%$ of these facilities are more than 50 years old and the demands for rehabilitation are increasing". In the United States, safety of existing navigation structures has historically been evaluated deterministically, using design criteria for new structures [2]. This often resulted in inconsistent estimates.

Over time, changes in loading conditions as well as material degradation introduce uncertainties which deterministic analysis does not effectively take into consideration. Creep of grout, relaxation of prestressed bar/tendon and possible underground corrosion contribute to the uncertainties in evaluation of existing concrete gravity structures. Therefore, reliability assessment for these structures has to be based on probabilistic methods.

An overview of a methodology for time-variant reliability assessment of existing rockanchored concrete gravity structures developed at the University of Colorado at Boulder is presented in this paper.

\section{ANCHORED MONOLITH STRUCTURES}

\subsection{Loading Conditions}

In the United States, there are many anchored monolith structures (also called gravity structures). The elevation of such a structure is schematically given in Fig.1. Some 
of them are about 100 years old. One of these structures was considered for reliability assessment. The detailed description of this structure is given in [3]. It was built at the beginning of this century, and after about seventy years in service the structure was strengthened with prestressed rock anchors. The details of the anchors are shown in Fig.2.

The loading conditions used in reliability analyses of existing gravity structures are generally the same as those used in the design of these structures [2]. They consist of four loading situations including normal operating condition (most critical combination of pools that routinely occur due to fluctuations in river flow), maintenance condition (dewatering), extreme operating conditions (higher pools), and catastrophic loading conditions (loss of lower pool or earthquake).

\subsection{Corrosion}

Over the years, monolith structures strengthened with prestressed rock anchors may be subject of various types of corrosion activities. This investigation deals exclusively with corrosion of anchor bars, assuming that the structure itself does not have appreciable deterioration. A survey of failure of rock anchors by Xanthakos [4] indicates that the life of a rock anchor is mainly controlled by corrosion which largely affects the unbonded or free length of anchor. The rate of corrosion penetration in anchor bar/tendon is governed by the aggressivity of the environment and the protection provided to the anchor in question.

The corrosion initiation is related to the presence of aggressive chemicals, such as chloride ions, beyond a threshold value (generally believed to be between $0.2 \%$ to $0.4 \%$ by weight of cement of chloride concentration) at the surface of steel. Immediately after reaching the threshold value (i.e., corrosion initiation time $t_{0}$ ) the propagation of corrosion results in material loss.

The material loss function is adapted from a power function fitted to experimental data of atmospheric corrosion penetration in steel coupons by Townsend and Zoccola[5]:

$$
C=a t_{1}^{\mathrm{b}}
$$

where, $C$ is corrosion penetration $(\mu m)$ per side, and $a$ and $b$ are regression coefficients.

Assuming analogy between atmospheric corrosion and underground corrosion penetration, eqn.(1) is used with a modifier factor $\alpha, C=\alpha a t_{1}^{\mathrm{b}}$. The modifier factor $\alpha$ takes into consideration the difference between the material loss expected in an underground environment and that in an atmospheric environment [3,6,7]. A close corroboration of observed data of material loss in sheet piles in ground by Buslov [8] supports this assumption.

\subsection{Prestress}

Longterm observation of dams shows that total prestress loss in rock anchors reach a maximum of $10 \%$ [9]. This value was also suggested by Littlejohn and Bruce [10] and Eberhardt and Veltrop [11] to cover the worst possible case of prestress loss, including losses due to creep in cement grout. With $10 \%$ loss due to relaxation and creep, the prestress loss model may be expressed as follows:

$$
P_{1}(t)=P_{o} \times\left[0.9+0.1 e^{(-\psi t)}\right]
$$

where, $P_{o}$ is the initial prestress force, $P_{1}(t)$ is the prestress force at time $t$ (years), and $\psi$ is a decay constant. With relaxation loss of $3 \%$ over 7 days, the resulting value of $\psi$ is 


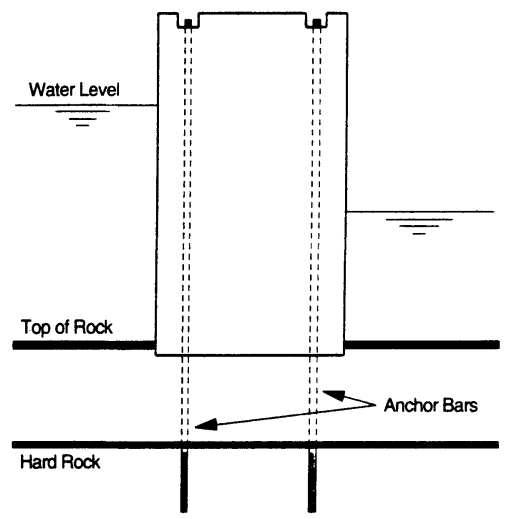

Figure 1. Schematic Elevation of a Monolith Structure

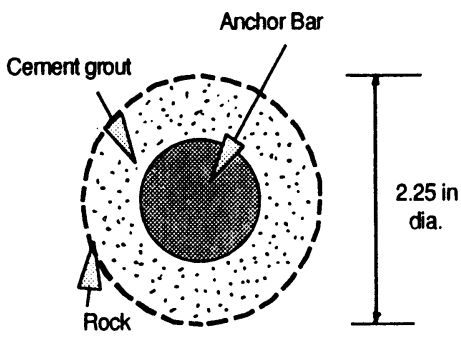

CROSS-SECTION AT FREE LENGTH

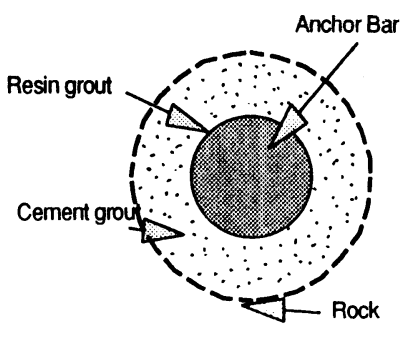

CROSS-SECTION AT FIXED LENGTH

Figure 2. Details of Anchors

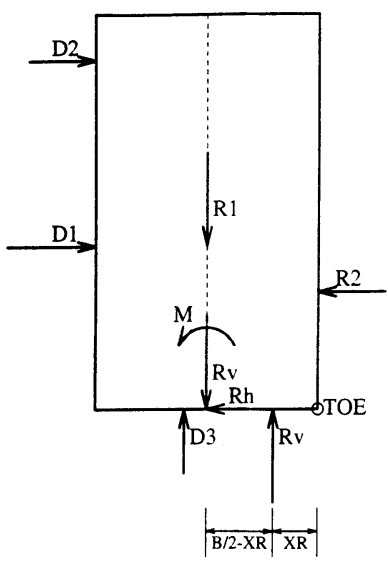

$\mathrm{M}=\mathrm{Net}$ Moment=MR-MO $=\operatorname{Rv}(B / 2-X R)$

$M R=$ Resisting Moment

$\mathrm{MO}=$ Overturning Moment

$\mathrm{Rv}=$ Net Vertical Force

$\mathrm{Rh}=$ Net Horizontal Force

$\mathrm{R} 1=$ Weight of Structure

R2=Resisting Water Force

D1=Overturning Water Force

D2=Impact Force

D3=Uplift Force

$\mathrm{XR}=$ Resultant Location

Figure 3. Resultant Location 
18.585 .

Assuming that the reduction of prestress force due to relaxation and creep occurs before corrosion loss takes effect, the relationship between the prestress force after loss due to relaxation, creep and corrosion at any point in time, $P_{2}(t)$, and the prestress force after loss only due to relaxation and creep, $P_{1}(t)$, may be established, from strain compatibility, as [3]:

$$
P_{2}(t)=P_{1}(t) \frac{l_{1}+l_{2}}{l_{2} \frac{A(o)}{A(t)}+l_{1}}
$$

where $A(o)=$ original cross-sectional area of the anchor bar, $A(t)=$ average cross-sectional area of the corroded anchor bar at time $t=t_{0}+t_{1}, l_{1}=$ part of the free length of the anchor bar not affected by corrosion, $l_{2}=$ part of the free length of the anchor bar affected by corrosion, and $P_{1}(t)=$ prestressing force after loss due to relaxation and creep. If the total free length is affected by corrosion, then $P_{2}(t)=P_{1}(t) A(t) / A(o)$.

\subsection{Variables}

The dimensions of anchors, underground strata conditions (characteristics and physical properties), corrosion parameters, physical properties of concrete and prestressing strands, and prestressing forces can be all characterized as random variables with known mean values and standard deviations. A list of such variables used for reliability analysis with respect to resultant location of an anchored monolith structure is included in Table 1.

Table 1

List of variables

\begin{tabular}{lrr} 
Variable & Mean & $\begin{array}{r}\text { Standard } \\
\text { Deviation }\end{array}$ \\
\hline Density of fractured base rock, $\gamma_{f}(\mathrm{kcf})$ & 0.160 & 0.016 \\
Density of monolith concrete, $\gamma_{\text {con }}(\mathrm{kcf})$ & 0.140 & 0.007 \\
Uplift factor, $E$ & -0.25 & 0.20 \\
Angle of internal friction of base rock, $\phi_{\text {rock }}$ (degree) & 30 & 6 \\
Diameter of anchor bar, $d$ (in) & 1.25 & 0.0375 \\
Regression coefficient, $a$ & 37.8 & 7.56 \\
Regression coefficient, $b$ & 0.749 & 0.1498 \\
Initial prestress force, $P_{o}$, in anchor type I (kips) & 112 & 8.96 \\
Initial prestress force, $P_{o}$, in anchor type II $(\mathrm{kips})$ & 93 & 7.44 \\
Yield stress of anchor bar, $f_{y}(\mathrm{ksi})$ & 129 & 3.225 \\
Part of free length not affected by corrosion, $l_{1}(\mathrm{ft})$ & 34.3 & 0.34 \\
Part of free length affected by corrosion, $l_{2}(\mathrm{ft})$ & 12.0 & 0.60 \\
Ultimate bond stress factor, $k$ & 0.15 & 0.075 \\
Time of exposure, $t$ (years) & $0-100$ & 0 \\
Model coefficient, $\alpha$ & $1 ; 2 ; 3$ & 0 \\
\hline
\end{tabular}

It may be noted that while many random variables have been considered in the reliability analysis, the level of water for various loading cases is considered as deterministic. 
In fact, four loading cases have been considered in the analysis. These cases are associated with the difference between the level of water in the upper and lower pools of $6.4 \mathrm{ft}, 8.2 \mathrm{ft}$, $25.4 \mathrm{ft}$, and $31 \mathrm{ft}$. Both reliability with respect to resultant location including overturning (rotational stability) and sliding reliability have been considered. In this paper, however, owing to space limitations, only the reliability with respect to resultant location will be briefly presented.

\section{ROTATIONAL STABILITY}

The probability that the resultant of all vertical forces, $R_{V}$, is located at the point of rotation (i.e., at the toe of the structure) is equivalent to the probability that the resisting moment equals the overturning moment. This situation of impending overturning is a true limit state. However, under these circumstances, overstressing of the structure or the foundation may result in tensile stresses at the base causing separation of the base from the foundation. As such, it is desirable to investigate the effect of varying resultant location $X_{R}$ measured from the toe (see Fig.3). If the resultant is located more than B/3 from the toe (B is the width of the structure/foundation at base), then the structure at the base will have $100 \%$ compression in the foundation contact area. Similarly, resultant locations, $X_{R}$, more than $\mathrm{B} / 6$ and $\mathrm{B} / 4$ from the toe correspond to different percentages of base compression. The limit states associated with these resultant locations can best be categorized as several transition states prior to reaching a true limit state, when the structure fails by overturning (i.e., $X_{R}=0$ ). General formulation of these transition state functions for a structure having $m \times n$ anchors subjected to overturning about the $\mathbf{Y}$-axis of rotation (see Fig.4) considers the following assumptions: (a) the monolith structure is rigid; (b) linear strain relationship exists among anchors in one row parallel to $\mathbf{X}$-axis; (c) all anchors have the same free length and same fixed length; and (d) all anchors get corroded at the same time and with the same corrosion rate.

The general limit state function against rotational instability is:

$$
g=M_{R}+\sum_{i=1}^{m} \sum_{j=1}^{n}\left[x_{m} f_{y} A_{m, j}(t)+x_{i} P_{2 i j}(t)\right]-M_{O}-R_{V} X_{R}=0
$$

where, $M_{R}$ is the resistance moment of monolith structure without anchors, $M_{O}$ is the overturning moment, $R_{V}$ is the resultant vertical force, $P_{2 i j}(t)$ is obtained from eqn.(3), $f_{y}$ is defined in Table 1, and the other terms are defined in Fig.3.

In what follows, the limit state of resultant location is used as a two-dimentional stability analysis to replace overturning analysis [2]. In fact, ref.[2] states "overturning is unlikely as a pure mode of failure, as foundation bearing and/or sliding failure would occur before the resultant reaches the toe".

\section{RELIABILITY ANALYSIS}

The general purpose structural reliability analysis program RELTRAN, based on first order reliability method, developed at the University of Colorado at Boulder [12], has been used to compute reliability indices of anchored monolith structures. The general 


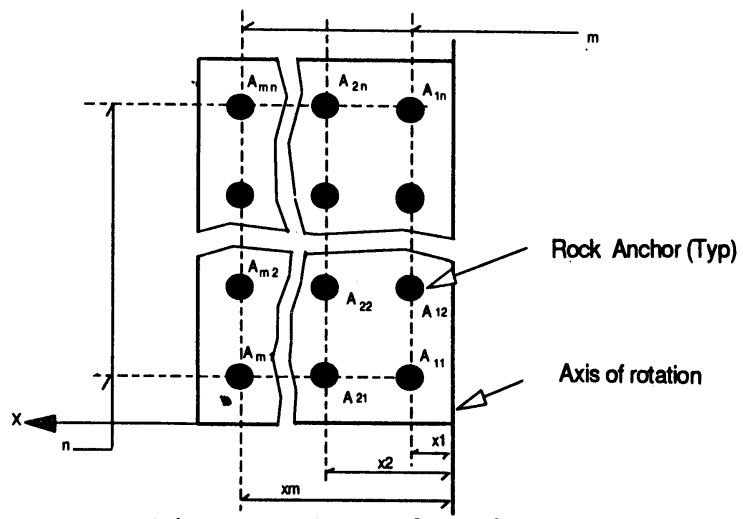

Figure 4. General Anchor Layout

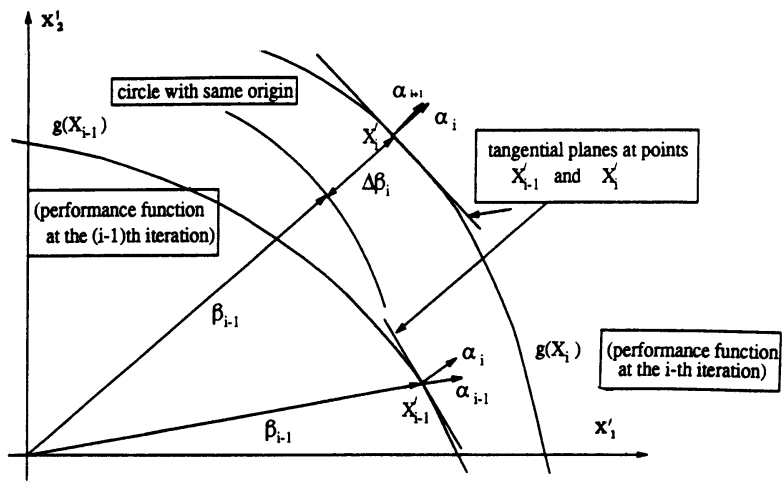

Figure 5. Geometrical Representation of RELTRAN Algorithm [12]

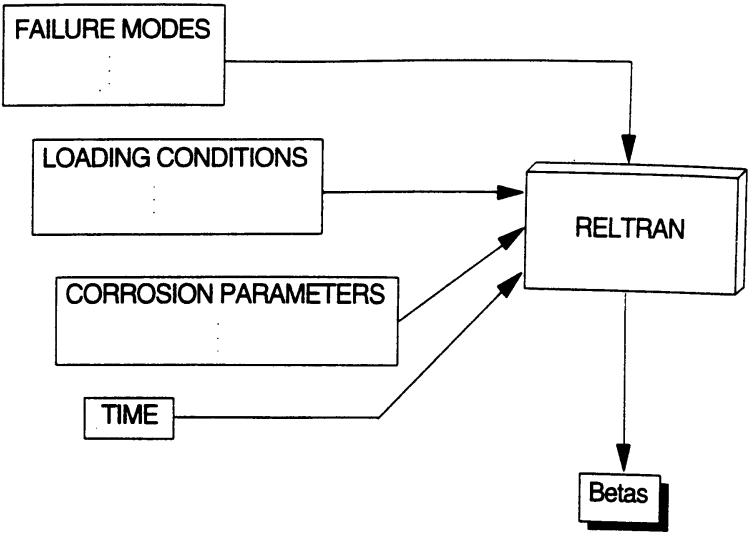

Figure 6. Use of RELTRAN in Time-Dependent Reliability Analysis 
illustration of RELTRAN's algorithm is shown in Fig.5 [12]. Time-variant reliability assessment is accomplished through repetitive use of RELTRAN for each time increment (see Fig.6).

\section{RESULTS}

For three loading conditions, Table 2 shows the results of time-variant reliability analyses of the anchored monolith structure whose characteristics are defined in Table 1, for four cases of resultant location (measured from the toe, see Fig.3): $X_{R}=0$ (overturning), $X_{R}=B / 6$ (resultant being in the middle two-thirds of the base), $X_{R}=B / 4$ (resultant being in the middle one-half of the base), and $X_{R}=B / 3$ (resultant being within the kern, $100 \%$ compression at the foundation-base area).

Table 2

Reliability Index for Resultant Location

\begin{tabular}{lcrrrrrr}
\hline Loading & Resultant & \multicolumn{5}{c}{ Reliability Index $\beta$ at Time $t$} \\
\cline { 3 - 8 } Conditions & Location $\left(X_{R}\right)$ & $0 \mathrm{yr}$ & $10 \mathrm{yr}$ & $20 \mathrm{yr}$ & $30 \mathrm{yr}$ & $40 \mathrm{yr}$ & $50 \mathrm{yr}$ \\
& 0 & 10.80 & 10.41 & 10.37 & 8.49 & 8.28 & 8.05 \\
Normal & $\mathrm{B} / 6$ & 8.49 & 8.03 & 7.95 & 5.30 & 4.76 & 4.41 \\
Operating & $\mathrm{B} / 4$ & 6.22 & 5.68 & 5.57 & 4.05 & 3.62 & 2.99 \\
& $\mathrm{~B} / 3$ & 1.80 & 1.08 & 0.97 & 0.85 & 0.74 & 0.63 \\
& 0 & 7.39 & 6.97 & 6.93 & 6.69 & 5.77 & 4.85 \\
High & $\mathrm{B} / 6$ & 4.29 & 3.78 & 3.72 & 3.64 & 3.22 & 2.84 \\
Water & $\mathrm{B} / 4$ & 1.24 & 0.64 & 0.56 & 0.49 & 0.42 & 0.35 \\
& $\mathrm{~B} / 3$ & $<0$ & $<0$ & $<0$ & $<0$ & $<0$ & $<0$ \\
& 0 & 7.48 & 7.17 & 7.14 & 7.11 & 6.44 & 5.58 \\
Maintenance & $\mathrm{B} / 6$ & 4.61 & 4.26 & 4.21 & 4.17 & 4.11 & 3.37 \\
& $\mathrm{~B} / 4$ & 2.06 & 1.68 & 1.62 & 1.58 & 1.53 & 1.48 \\
& $\mathrm{~B} / 3$ & $<0$ & $<0$ & $<0$ & $<0$ & $<0$ & $<0$ \\
\hline
\end{tabular}

The three loading conditions considered included normal operating, high water, and maintenance. These conditions were associated with different water levels of the upper and the lower pools [3]. The corrosion model coefficient assumed in computations was $\alpha=2$, and the parameters $a$ and $b$ were considered random variables with means $\bar{a}=37.8, \bar{b}=0.749$, coefficients of variations $V(a)=V(b)=20 \%$, and correlation coefficient $\rho(\mathrm{a}, \mathrm{b})=0.5$.

\section{CONCLUSIONS}

In conclusion, it is emphasized that although the proposed time-dependent reliabilitybased assessment methodology for anchored monolith structures appears to be adequate, much efforts are needed in connection with : (a) developing resistance models for damaged monolith structures, (b) developing practical risk-based criteria for reliability assessment of existing monolith structures under time-dependent effects, and (c) developing a suitable 
methodology (possibly based on multi-objective reliability-based optimization) for safety management of navigation structures by considering risk-benefit tradeoffs.

In order to realize these ambitious goals, interdisciplinary research interfacing structural analysis, reliability, and optimization techniques is necessary.

\section{ACKNOWLEDGEMENT}

The support of this research by the U.S. Army Corps of Engineers under Contract No. DACW 39-92-K-0032 is gratefully acknowledged. The results, opinions, and conclusions expressed in this paper are solely those of the authors and do not necessarily represent those of the sponsor.

\section{REFERENCES}

1. ETL-1110-2-532, U.S. Army Corps of Engineers, Washington, D.C. (1992).

2. ETL-1110-2-321, U.S. Army Corps of Engineers, Washington, D.C. (1993).

3. D. M. Frangopol, M. Chakravorty, and J. E. Pytte, Time-Variant Reliability of Rock Anchors for Navigation Structures, Final Research Report for the U.S. Army Corps of Engineers, University of Colorado, Boulder, Colorado (1993).

4. P. P. Xanthakos, Ground Anchors and Anchored Structures, John Wiley and Sons, New York (1991).

5. H. E. Townsend and J. C. Zoccola, Eight-year Atmospheric Corrosion Performance of Weathering Steel in Industrial, Rural and Marine Environments, ASTM, STP No.767, Penn.(1982).

6. M. Chakravorty, D. M. Frangopol, R. L. Mosher, and J. E. Pytte,Time-Dependent Reliability of Rock-Anchored Structures, Reliability Engineering \& System Safety (1995) accepted.

7. D. M. Frangopol, M. Chakravorty, R. L. Mosher, and J. E. Pytte, Reliability Assessment of Rock-Anchored Gravity Structures, Proceedings ICASP 6, Paris, France, (1995) accepted.

8. V. Buslov, Corrosion of Steel Sheet Piles in Port Structures, Journal of Waterway Port Coastal and Ocean Engineering, ASCE, Vol.109, No.1 (1983).

9. M. P. Collins and D. Mitchell D, Prestressed Concrete Structures, Prentice Hall, New Jersey, (1991).

10.G. S. Littlejohn and D. A. Bruce, State-of-the Art - Rock Anchors, Foundation Publications Ltd., Sussex, England (1977).

11.A. Eberhardt and J. A. Veltrop, Prestressed Anchorage for Large Trainter Gate, Journal of Structural Div., ASCE, 90(ST6), (1964).

12.Y-H. Lee, S. Hendawi, and D. M. Frangopol, "RELTRAN: A Structural Reliability Analysis Program: Version 2.0", Rep. No. CU SR-9316, University of Colorado, Boulder, Colorado (1993). 